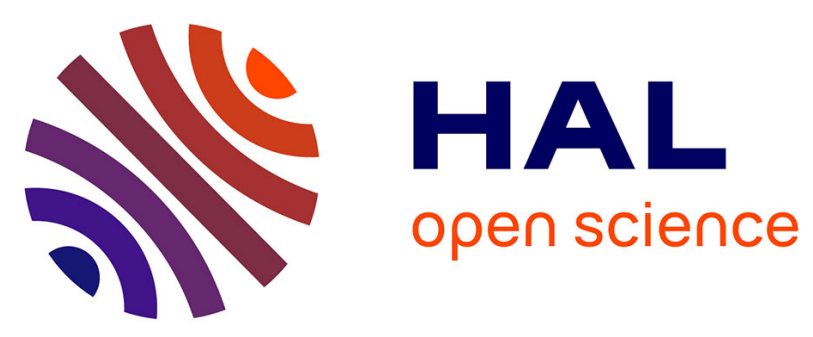

\title{
Uncertainties in Mean River Discharge Estimates Associated With Satellite Altimeter Temporal Sampling Intervals: A Case Study for the Annual Peak Flow in the Context of the Future SWOT Hydrology Mission
}

\author{
F. Papa, Sylvain Biancamaria, C. Lion, W. Rossow
}

\section{To cite this version:}

F. Papa, Sylvain Biancamaria, C. Lion, W. Rossow. Uncertainties in Mean River Discharge Estimates Associated With Satellite Altimeter Temporal Sampling Intervals: A Case Study for the Annual Peak Flow in the Context of the Future SWOT Hydrology Mission. IEEE Geoscience and Remote Sensing Letters, 2012, 9 (4), pp.569-573. 10.1109/LGRS.2011.2174958 . hal-02137391

\author{
HAL Id: hal-02137391 \\ https://hal.science/hal-02137391
}

Submitted on 27 Aug 2019

HAL is a multi-disciplinary open access archive for the deposit and dissemination of scientific research documents, whether they are published or not. The documents may come from teaching and research institutions in France or abroad, or from public or private research centers.
L'archive ouverte pluridisciplinaire $\mathbf{H A L}$, est destinée au dépôt et à la diffusion de documents scientifiques de niveau recherche, publiés ou non, émanant des établissements d'enseignement et de recherche français ou étrangers, des laboratoires publics ou privés. 

temporal sampling intervals: a case study for the annual peak flow in the context of the future SWOT hydrology mission.

4

6

7

(1) LEGOS/CNRS-CNES-IRD-UPS, Toulouse, France

8

(2) NOAA-CREST, City College of New York, New York, USA

9

*Corresponding author: fabrice.papa@ird.fr

13 Published in IEEE Geoscience and Remote Sensing Letters, doi:10.1109/LGRS.2011.2174958 
Abstract- In the context of the Surface Water and Ocean Topography mission (SWOT), investigations are needed to refine the error budget for discharge estimations. This study proposes to evaluate the uncertainties in the estimation of mean river discharge around the seasonal peak flow due to the satellite temporal sampling intervals. The daily time series of in situ river discharge measurements for 11 large rivers are used to analyze the uncertainties associated with the sampling of four altimeter repeat cycles: the 35, 22 and 10-day repeat cycles in the nadir-looking configuration of current altimeters and the 22-day repeat cycle in the SWOT wide-swath configuration, where a given location is observed every cycle twice at the equator and six times in higher latitudes. Results show that for boreal rivers, a sampling of 35 or 22 days from current nadir altimeters is too coarse to give an accurate estimate of the average discharge around the seasonal peak flow, whereas, for all watersheds, the uncertainties associated with a 10-day repeat cycle or the 22-day repeat cycle in the SWOT wide-swath configuration are within the range of acceptable uncertainties (15-20\%). In addition, the absolute maximum mean discharge uncertainties associated with the SWOT time sampling have a strong relationship with the variance of the river discharge. This suggests that, rather than the commonly used basin area, the magnitude of the short-time-scale variance of the discharge could be used as predictor of the uncertainties associated with temporal sampling intervals when estimating average discharge around the seasonal peak flow.

\section{Introduction}

Continental freshwater runoff or discharge, as well as the spatial distribution and storage of fresh water on land, is a key parameter of the global water cycle and play an important role in driving the climate system [1]. Moreover, natural disasters of hydrological origin dramatically affect human societies, with large economic losses during water-related extreme events such as floods or droughts. 
Despite a widespread recognition of the need for better observations at global scale, surface freshwater measurements are still limited mostly to sparse in situ networks of gauges, the number of which has dramatically decreased during the last two decades, especially in remote areas [1]. In addition, public access to recent observations is generally restricted.

Over the last twenty years, satellite remote sensing techniques have become more useful for hydrologic investigations [1], [2], [3]. In particular, satellite altimetry (TOPEX-Poseidon (T-P), Jason-2, ERS-1/2, GFO and ENVISAT missions) has been used for systematic monitoring of water levels in large rivers, lakes and floodplains [4] and several studies have demonstrated the capability of using these sensors locally for estimating river discharge in large rivers (still limited to rivers with a width of few kilometers), including the Ganges-Brahmaputra [5] or the Ob River [6]. Indeed, the construction of empirical regression curves between altimetry-derived river water heights in large river basins and in situ measurements of river discharge can provide altimetry-based discharge estimates for times when in situ discharge observations are missing, or even, to extend the time-series of river discharge forwards/backwards. This technique has several limitations [1], [5], [7], such as, to name a few, the quality of the current altimetry data themselves over continental water bodies, the current altimeter sampling frequency along track, and the spatial coverage of current satellite altimetry missions which is not adequate for global scale investigations due to their orbit track separation at the equator (few tens to hundreds of kilometers). In addition, a major drawback in the use of current altimetric measurements to monitor river stage and discharge is the temporal sampling rate at a given location, which is 10 days for T-P/Jason-2 and 35 days for ERS-1/2 and ENVISAT. With such space/time sampling intervals, current satellite altimeters cannot compete with observations made daily or twice daily by in situ gauges, a frequency required to study local hydrological processes, to evaluate flood risk or for the management of water resources. Nevertheless, for studies related to climate, the use of current radar altimetry is still extremely valuable as a complement to 
ground-based observations [5].

The future wide swath altimetry measurements made by the Surface Water and Ocean Topography (SWOT) satellite mission (to be launched in 2020) will provide high-resolution characterization of water surface elevations with 2D global maps of terrestrial surface water extent and storage changes and discharge estimates [1]. Previous studies [1], [7], [8], [9] have reviewed the expected accuracy of the variables that will be measured and investigated the different errors which will affect SWOT data and the derived discharge. Instantaneous discharge estimated globally from SWOT are expected to have errors below $25 \%$, even if locally these errors might be higher for ungauged basins. These errors are primarily due to errors on SWOT measurements (error on water elevation will be equal or below $10 \mathrm{~cm}$, error on the water mask will be around $20 \%$ of the true area and error on the river slope will be equal or below $1 \mathrm{~cm} / 1 \mathrm{~km})$. Other anticipated sources of error come from ancillary data needed to compute the discharge (bathymetry and friction coefficient). When estimating monthly or average river discharge from instantaneous discharge estimates, the temporal resolution of the satellite observations will also be a source of uncertainties.

In this paper, we focus on the evaluation of the uncertainties due to the temporal sampling on the estimation of mean river discharge around the annual peak flow. Even though it is important to accurately monitor low flow and high flow discharge, the hydrologic events around the yearly peak flow are of particular importance as they are generally associated with the flood waves.

The in situ measurement and observation of river discharge are in general well established and, ideally, the goal for in situ discharge data accuracy is within $+-5 \%$ of the true value. However, given the difficulties to measure the depth and velocities (and consequently the true discharge), especially in large and strong- flowing rivers, the community agrees that a 15-20\% accuracy is generally acceptable. When using radar altimetry, the accuracy of river discharge 
estimates depends, among other factors, on the satellite temporal sampling: for instance, mean discharge estimates will likely be more accurate for a river with several views per orbit than for a river with one revisit. Former and current radar altimeters (T/P, Jason-2, ERS-1/2, ENVISAT) view nadir along the orbit track, so a particular point is observed only once every repeat cycle except at overpasses (ascending and descending views) where two measurements are made. Given the inter-track interval $(\sim 300 \mathrm{~km}$ and $\sim 80 \mathrm{~km}$ at the equator respectively for TP/Jason-2 and ERS-1/2 and ENVISAT) most of continental water bodies that are monitored are sampled only once and not always at an adequate location to measure river discharges. Unlike a nadir-viewing instrument, wide-swath instrument might see the same location from adjacent orbits, so a particular point might be observed several times every repeat cycle. With its wide swath altimetry measurements, the SWOT mission will offer a global spatial coverage with the number of views of a given location per cycle varying as function of latitude, and ranging from twice at the equator to more than 6 times at high latitudes. At the time of writing, SWOT nominal orbit will have a 22-day repeat period and a global coverage of the Earth up to the latitudes $78^{\circ}$ North and South.

Using T-P (10-day repeat cycle), ERS-2 and ENVISAT (35-day repeat cycle) altimeters, [5] and [6] showed that the errors of the discharge estimated indirectly from altimetric measurements (at 10 days, monthly or annual time scales) are on average well within the range of acceptable errors (5 to 20\%). However, the impact of the temporal sampling on the accuracy of the river discharge estimates during the annual peak flow is still not well known. For instance, if all overpasses occurred during flood stage, it leads to an overestimation of the average discharge based on these observations whereas in other cases, the sensor may completely miss the peak flow event. Over the Ganges-Brahmaputra river system, [5] showed that even with a coarse 35 day interval sampling interval (ERS-2/ENVISAT), the underestimation or overestimation of the in situ mean discharge in general never exceeds $20 \%$. 
115 Using a similar methodology, the goal of this study is to assess the effects that different 116 altimeter repeat cycles (10-day, 22-day, 35-day temporal sampling and with a "real" SWOT

117 repeat cycle in the wide-swath configuration) will have in estimating mean discharge around 118 the yearly peak flow. For this we will use daily in situ gauge measurements from 11 large rivers 119 around the world. Section 2 presents and discusses the datasets and the methodology. Section 3 120 presents and discusses the results. The conclusions are given in Section 4.

\section{Dataset and methodology}

We analyze the daily time series of in situ river discharge measurements for 11 large rivers (Table 1), which represent a fair sample of different environments, from the Tropics to Boreal regions. These time series are provided by 1) the HYBAM project (www.ore-hybam.org) for the Amazon and Congo Rivers and 2) the Global Runoff Data Center [10] for the other rivers. These 11 rivers were selected because of the availability of fairly long (more than a decade), accurate (evaluated) and continuous measurements.

Using these datasets, we performed the following analysis for each of the 11 rivers, with $\mathrm{T}$ representing the repeat cycle of the satellite $(10,22$ or 35 days):

The date of the peak flow is identified for each year in the in situ record. A sliding window of $\mathrm{T}$ days is applied to the record, starting $\mathrm{T}$ days before the peak flow and going to the peak

133 flow date in each year. The window moves with one-day steps; at each step, the average 134 discharge is calculated using all $\mathrm{T}$ days in the window (the true mean) and using only the two 135 end-points. The same calculation is done for all the years for which in situ discharge is 136 available (Table 1). The difference (in percent of true mean) between the two means at each 137 step is averaged over the years. The analysis is done for each of the 11 stations.

138 In parallel, "true" SWOT observation times were determined for each of the 11 gauge 139 locations by calculating the number of times each gauge location is viewed from the satellite 
140 during a cycle using the relationship between the number of revisits and latitude [7]. The same

141 analysis is done as previously but instead of considering only the 2-end points of the 22-day

142 repeat cycle, we consider all observations of the target within the 22-day repeat cycle. The

143 numbers of revisits per cycle for each station is given in Table 1, but note that the SWOT

144 sampling is not uniformly distributed in time during one repeat cycle. Depending on the

145 location, a target may be observed twice on two consecutive days and then not be sampled

146 again for the next ten days. In our case, for the Amazon at Obidos, two observations are made

147 on the $16^{\text {th }}$ and $17^{\text {th }}$ day of the cycle whereas there are up to six observations for the Lena River

148 in Siberia, with irregular sampling on the $2^{\text {nd }} 5^{\text {th }}, 8^{\text {th }}, 11^{\text {th }}, 18$ th and $21^{\text {st }}$ days of the cycle.

149 Globally, the maximum time between two observations for a target is 13 days [7]. Note also,

150 that in this study, we have only considered the SWOT measurements that observe the gauge

151 location directly. However, because of its wide swath, SWOT will also measure water

152 elevations upstream and downstream of the gauge location, which could then be used to infer

153 water elevation at the gauge location using hydrodynamic models or statistical relationships

154 and therefore, increase the number of samples on the mean discharge estimate [11]. Thus, the

155 SWOT temporal sampling uncertainty computed in this study corresponds to the maximum 156 expected error.

157 Finally, in the present study, we are interested in the effect of temporal sampling only. It is 158 important to remind here that these uncertainties represent only a source of error among many

159 other uncertainties associated with the estimates of instantaneous and mean river discharge

160 from altimeter data. Indeed, as discussed in the introduction, the river water height needs to be

161 first converted into discharge and such retrieval errors [7, 9] will also largely impact the results.

162 These effects will not be discussed here.

3. Results and Discussion. 

the 11 stations. The $\mathrm{x}$-axis values represent the lower endpoint of a $\mathrm{T}$ day sliding window. For 0 , the lower end-point of the time window is at peak minus $\mathrm{T}$ days and the upper end-point is on the day of the peak discharge. At 5 , the lower end is at peak minus $\mathrm{T}$ plus 5 days and the upper end is at peak plus 5 days and so on. The y-axis represents for each step the average difference over the years between the average discharge calculated using only the two endpoints and the true mean discharge calculated using all days in the time window. The y-axis values are expressed in percent of the true mean.

As expected, with the 35-day window (Figure 1a, the case of ERS/ENVISAT altimeters),

174 the uncertainties are the largest, with big differences from river to river. The largest differences 175 are found for the three basins in Siberia, the Ob, the Yenisey and the Lena, for which river discharge is characterized by a sharp and rapid increase at the end of the snowmelt season when the river ice breaks up. High river discharge values last only few weeks before a sharp decrease. For instance, for the Lena River, when one of the end-points is within +-5 days of the date of the peak flow, the average overestimation can be more than $200 \%$ of the true mean.

180 When the two samples bracket the peak flow date (around day 14 to 25), the underestimation is between 30 to more than $50 \%$. The Yenisey and the Ob Rivers show the same patterns, but with smaller over/underestimation, especially for the Ob River for which the flood season and high peak flow last longer [12,13]. For mid-latitude and tropical watersheds, the results show

184 differences within the acceptable range of uncertainties for river discharges, i.e. around +-20\%.

185 In most tropical watersheds (Amazon, Niger, Orinoco...), when one of the end-points is on the date of the peak flow (day=0 for instance), the mean discharge using the two end-points overestimates the true 35 -day mean river discharge by about $10 \%$. Then the differences show almost permanent underestimations of the 35-day mean discharge as soon as the peak flow is missed by 3 to 4 days. Moving the window forward shows that the differences (underestimates) 
190 are less than 5\%, even with a 35-day sampling interval, and reach a maximum when the two 191 samples bracket the peak flow date. The differences are larger for mid-latitudes watersheds, but 192 the differences are generally less than $15 \%$ with a maximum underestimation of $\sim 20 \%$ for the 193 Mississippi. Note that among the tropical watersheds, the Irrawaddy shows the largest 194 uncertainties (maximum and minimum underestimation above 20\%) which might be explained 195 by sharp increases and variability of the river discharge value during the monsoon season. This 196 behavior is similar to the one found in [5] for two other large rivers of the region, the Ganges 197 and the Brahmaputra.

198 As also expected, a ten-day sampling (Figure 1b), which is the repeat cycle of Topex199 Poseidon and Jason-2 radar altimeters, leads to much smaller errors when estimating the 200 discharge around the peak flow. Tropical basins, such as the Amazon, the Orinoco or the 201 Congo, show almost no difference between the 10-day bracket and the true mean discharge 202 (uncertainties below 2\%). With a 10-day sampling interval, all rivers except the Lena are within $203+-20 \%$. The maximum error for the Lena is an underestimation (25\%) when the two samples 204 bracket the peak flow date (day 5). Nevertheless, uncertainties for around day 0 for the Lena 205 are reduced from more than $200 \%$ with a 35-day repeat cycle to $\sim 20 \%$. For the Yenisey and the 206 Irrawaddy Rivers, the large uncertainties noticed with the 35-day sample are reduced to less 207 than $10 \%$ with a 10 -day repeat cycle.

208 Figure 1c gives the results for a 22-day repeat cycle for the SWOT mission with only nadir 209 view, i.e. when the targets are visited only once every 22 days. As an intermediate case 210 between the 35 and 10-day sampling intervals, the results still show fairly good estimates of 211 mean discharge around the peak flow for most tropical basins (Amazon, Congo, Orinoco) and 212 uncertainties in mid-latitude basins on the order of $10 \%$. The Irrawaddy and Yenisey have 213 largest errors but with maximum over/underestimations around 20\%. For the Lena River, a 214 sampling at twenty-two days is still too coarse to give an accurate estimate of the peak flow 
mean discharge with uncertainties ranging from $\sim 100 \%$ to $-40 \%$.

However, as mentioned earlier, "true" SWOT observation times are more frequent per orbit

217 repeat cycle with each gauge location sampled at least twice within a 22-day repeat cycle.

218 Using the real SWOT orbit sampling (Table 1), Figure 2 shows that the errors on estimated

219 discharge around the peak flow are greatly reduced and well within the range of acceptable

220 uncertainties for all 11 rivers. For the boreal and mid-latitudes basins (Figure 2a), the

221 over/underestimation of mean discharges is always under $20 \%$. The Lena, which is now

222 sampled up to 6 times in a cycle also shows uncertainties within this range. For the Ob River,

223 which already showed acceptable errors with a 22-day cycle (Figure 1c) is now sampled six

224 times in a true SWOT configuration, reducing uncertainties less than 5\%.

225 For the tropical watersheds (Figure 2b, 2 revisits minimum as in Table 1), all associated uncertainties are below 10\%, except for the Irrawaddy, which still shows larger errors (overestimation of $\sim 10 \%$ and underestimation of $\sim 20 \%$ ) even when it is sampled twice. For the Amazon, the Congo, the Mekong, the Orinoco, the uncertainties are on the order of a few percent. Thus, these results show that for the 11 rivers considered here, the uncertainties associated with SWOT temporal sampling when estimating mean discharge around the annual peak flow are well within the range of acceptable errors.

Absolute maximum mean discharge errors for each river (as in Figure 2a and $2 \mathrm{~b}$ ) have been plotted as a function of the percentage of river discharge variance for frequencies above 1/(20 234 days) (Figure 3). This percentage is computed as follows. For daily each discharge time-series 235 for the 11 rivers, a Fourier transform is calculated, and the integral of its variance (which is the square of the Fourier transform amplitude) over all time scales less than 20 days computed as a 237 percentage of the total variance. This percentage gives the relative contribution of frequencies 238 above 1/(20 days) to the discharge variance, and is expected to be larger for rivers with 239 significant variability at shorter time scale. Figure 3 shows that the temporal sampling error is 
associated with the short-time-scale variability of the river discharge time series. A regression analysis gives a quantitatively estimate of the relationship between discharge variance and

242 SWOT temporal sampling errors in a form of a power law, statistically significant at $99 \%$ 243 confidence level $\left(R^{2}=0.87\right.$ with 11 points, $p$-values $<0.01$ with $\left.|R|>0.735\right)$. Quite logically, for 244 rivers with large short-time-scale variance, typically the boreal rivers with freeze/thaw cycles 245 and the monsoon-affected Irrawaddy, the SWOT sampling error is larger. Usually, temporal sampling errors on mean river discharge are parameterized as a function of the river catchments area [7]. However, we show that in the case of estimates of the mean discharge around the seasonal peak flow, the uncertainty has a strong relationship with the variance of the river

249 discharge. In the case of these 11 large rivers, the correlation between the absolute discharge 250 errors and the catchment's area is only $\mathrm{R}^{2}=0.18$. Thus, the magnitude of the short-time-scale variance is a stronger predictor of the peak discharge error than the basin area. Although this analysis only had 11 samples, we suggest that the relationship with the variance could then be a new tool to infer the quality of future SWOT measurements at other gauge locations, if some past discharge time series is available to calibrate the relationship.

\section{Conclusion.}

This study reports a first effort to evaluate the uncertainties in the estimation of mean river discharge around the seasonal peak flow due to satellite altimeters temporal sampling intervals. 259 Analyzing the daily time series of in situ river discharge measurements for 11 large rivers in 260 different environments, the results show that for high latitudes rivers, a sampling of 35 or 22 261 days in the nadir-looking configuration of current altimeter mission is too coarse to give an 262 accurate estimate of the average discharge around the seasonal peak flow. For tropical 263 watersheds however, such time sampling intervals lead to uncertainties that generally never 264 exceed $20 \%$ and thus are in the range of uncertainties acceptable for river discharge 
estimations. On the other hand, the uncertainties associated with a 10-day repeat cycle are well

within the range of acceptable errors from Tropical to Siberian rivers. Thanks to its wide swath

altimetry technique, which will enable to observe a given location at least twice at the equator

and up to six times in high latitudes every repeat cycle, the uncertainty due to SWOT time

sampling on the average discharge around the seasonal peak flow is greatly reduced when

compared to a 22-day repeat cycle instrument with a nadir looking angle. We found that these

uncertainties are generally well within the range of acceptable errors for boreal watersheds

(absolute maximum mean discharge uncertainties from 5 to 20\%), mid-latitudes watersheds

(absolute maximum mean discharge uncertainties $\sim 10 \%$ ) and tropical watersheds (absolute maximum mean discharge uncertainties from 2 to $\sim 20 \%$ ). Moreover, we find that absolute

maximum mean discharge uncertainties around the seasonal peak flow have a strong relationship with the variance of the river discharge. Thus, around the peak flow, we suggest

that the magnitude of the short-time-scale variance of the discharge could be used as predictor of the uncertainties rather than the commonly used basin area.

The future launch of the SWOT mission in 2020 will represent a step increase for continental hydrology and further studies are needed to refine the SWOT error budget for discharge estimates. For instance, the uncertainties for smaller rivers $(\sim 100 \mathrm{~m}$ to $\sim 1 \mathrm{~km}$ width$)$ have not been addressed here and require further investigations. Moreover, we address in this study the source of errors due to the temporal sampling of the satellite only, but in reality it will combined with other sources of uncertainty. These issues need to be addressed in future works.

\section{References}

[1] D. E. Alsdorf, E. Rodriguez, and D. P. Lettenmaier, "Measuring surface water from space," Rev. Geophys., vol. 45, no. 2, p. RG2002, 2007, DOI: 10.1029/2006RG000197.

[2] J.F. Crétaux, A.V. Kouraev, F. Papa, M. Bergé-Nguyen, A. Cazenave, N. Aladin, and I.S. Plotnikov, "Evolution of sea level of the big Aral Sea from satellite altimetry and its implications for water balance", J. Great Lakes Res., vol. 31, pp. 520-534, 2005.

[3] F. Papa, C. Prigent, F. Aires, C. Jimenez, W.B. Rossow, and E. Matthews, "Interannual variability of surface water extent at global scale", 1993-2004, J. Geophys. Res., 115, D12111, 2010, doi:10.1029/2009JD012674. 
330 Table 1: Information on the daily in situ river discharge time series used in this study: River

331 name, Gauge station name and location, first and last year of the available time series, catchment's area, mean value and standard deviation (STD) for the entire daily discharge time series and the number of views of the a given gauge station per SWOT cycle.

\begin{tabular}{|l|l|c|c|c|c|}
\hline $\begin{array}{l}\text { River } \\
\text { Name }\end{array}$ & Station Name and locations & Time series & $\begin{array}{c}\text { Catchment area } \\
\left(\mathrm{km}^{2}\right)\end{array}$ & $\begin{array}{c}\text { Mean Discharge/ } \\
\text { STD }\left(\mathrm{m}^{3} / \mathrm{s}\right)\end{array}$ & $\begin{array}{c}\text { Number of } \\
\text { samples per } \\
\text { SWOT cycle }\end{array}$ \\
\hline Amazon & Obidos $\left(1.92^{\circ} \mathrm{S} ; 55.67^{\circ} \mathrm{W}\right)$ & $1968-2008$ & 4618000 & $172700 / 49840$ & 2 \\
\hline Congo & Brazzaville $\left(4.25^{\circ} \mathrm{S} ; 15.28^{\circ} \mathrm{E}\right)$ & $1968-2008$ & 3500000 & $40500 / 9300$ & 2 \\
\hline
\end{tabular}




\begin{tabular}{|l|l|c|c|c|c|}
\hline Danube & Ceatal Izmail $\left(45.21^{\circ} \mathrm{N} ; 28.72^{\circ} \mathrm{E}\right)$ & $1954-2008$ & 807000 & $6580 / 2550$ & 2 \\
\hline Irrawaddy & Sagaing $\left(21.98^{\circ} \mathrm{N} ; 96.10^{\circ} \mathrm{E}\right)$ & $1978-1988$ & 117900 & $8170 / 6820$ & 2 \\
\hline Lena & Kusur $\left(70.70^{\circ} \mathrm{N} ; 127.65^{\circ} \mathrm{E}\right)$ & $1954-2003$ & 2430000 & $16950 / 23860$ & 6 \\
\hline Mekong & Phnom Penh $\left(11.58^{\circ} \mathrm{N} ; 104.96^{\circ} \mathrm{E}\right)$ & $1960-1973$ & 663000 & $13305 / 13300$ & 2 \\
\hline Mississippi & Vicksburg, MS $\left(32.31^{\circ} \mathrm{N} ; 90.95^{\circ} \mathrm{W}\right)$ & $1954-1999$ & 2964000 & $17370 / 9620$ & 2 \\
\hline Niger & Lokoja $\left(7.80^{\circ} \mathrm{N} ; 6.77^{\circ} \mathrm{E}\right)$ & $1970-1993$ & 2077000 & $4830 / 4890$ & 2 \\
\hline Ob & Shalekard $\left(66.57^{\circ} \mathrm{N} ; 66.53^{\circ} \mathrm{E}\right)$ & $1954-1999$ & 2949000 & $12800 / 11190$ & 6 \\
\hline Orinoco & Puente Angosta $\left(8.15^{\circ} \mathrm{N} ; 63.60^{\circ} \mathrm{W}\right)$ & $1950-1989$ & 836000 & $31650 / 21690$ & 2 \\
\hline Yenisey & Igarka $\left(67.48^{\circ} \mathrm{N} ; 86.50^{\circ} \mathrm{E}\right)$ & $1980-2003$ & 2440000 & $19170 / 23180$ & 3 \\
\hline
\end{tabular}

334

336 Figures Caption:

337 Figure 1: Uncertainty of the 35-day (a) and 10-day (b) and 22-day (c) sampling intervals in the

338 estimation of mean river discharge around the yearly peak flow for 11 large rivers (see text for

339 details and the method): the Ob (black solid line), the Yenissey (black doted line), the Lena

340 (black dashed line), the Orinoco (red solid line), the Amazon (red dashed line), the Congo

341 (green solid line), the Niger (green dashed line), the Irrawaddy (blue solid line), the Mekong

342 (Blue dashed line), the Danube (purple solid line), and the Mississippi (purple dashed line).

345 Figure 2: Same as Figure 1 with the SWOT 22-day repeat cycle but taking into account the

346 number of SWOT views per cycle. For clarity, we separate the rivers in boreal/mid-latitudes

347 environments (a) and the ones located in the Tropics (b)

349 Figure 3: Relationship between the uncertainties on the monthly discharge estimates around

350 the yearly peak flow in the context of SWOT 22-day repeat cycle versus the percentage of total

351 discharge variance for frequencies above 1/(20 days) estimated for the 11 stations.

\section{Figures:}



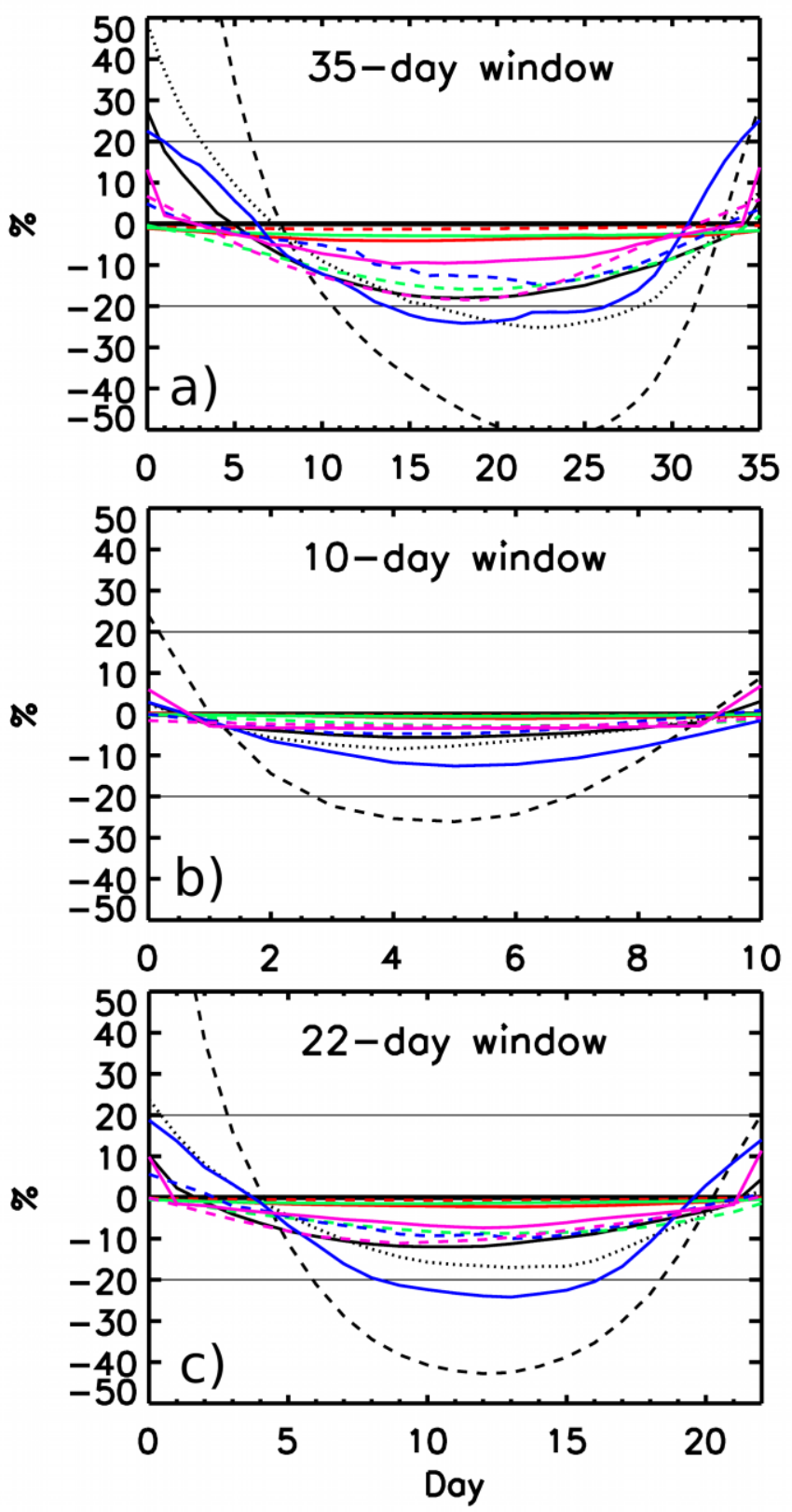
Figure 1. 

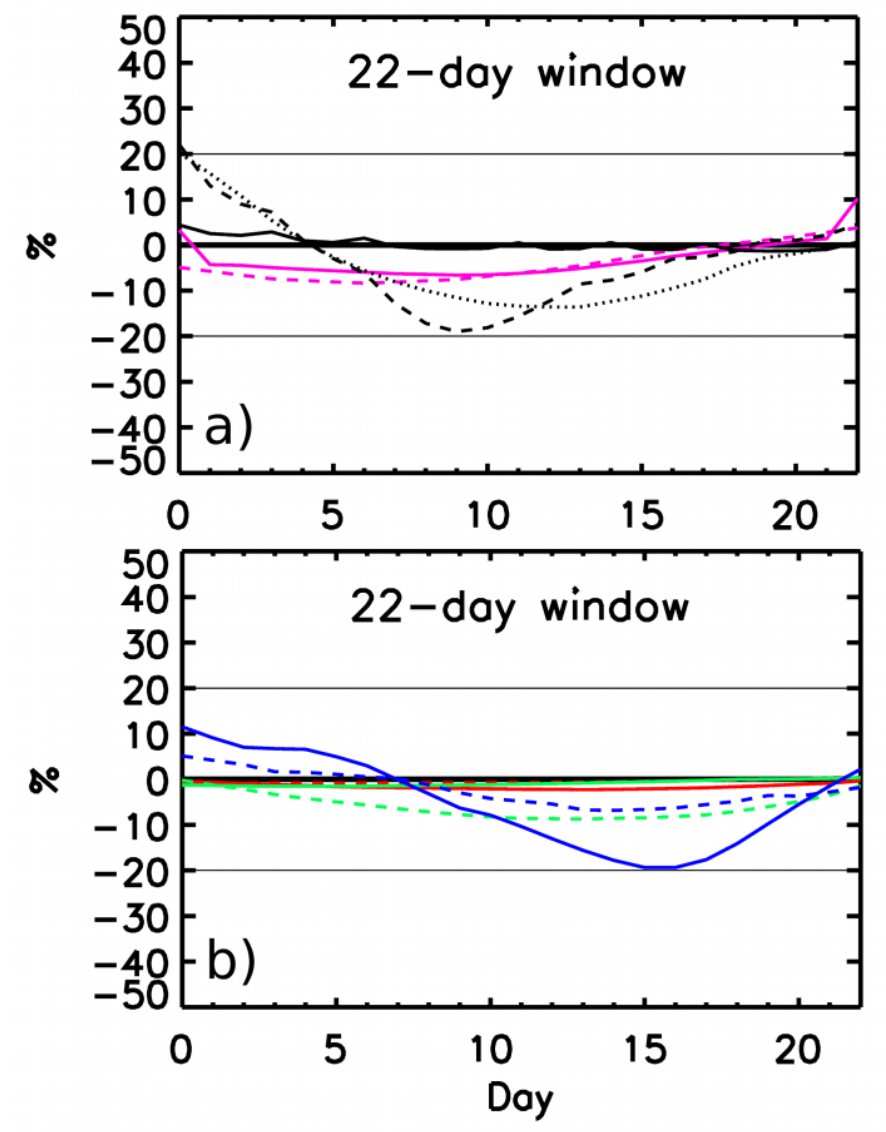

359

Figure 2.

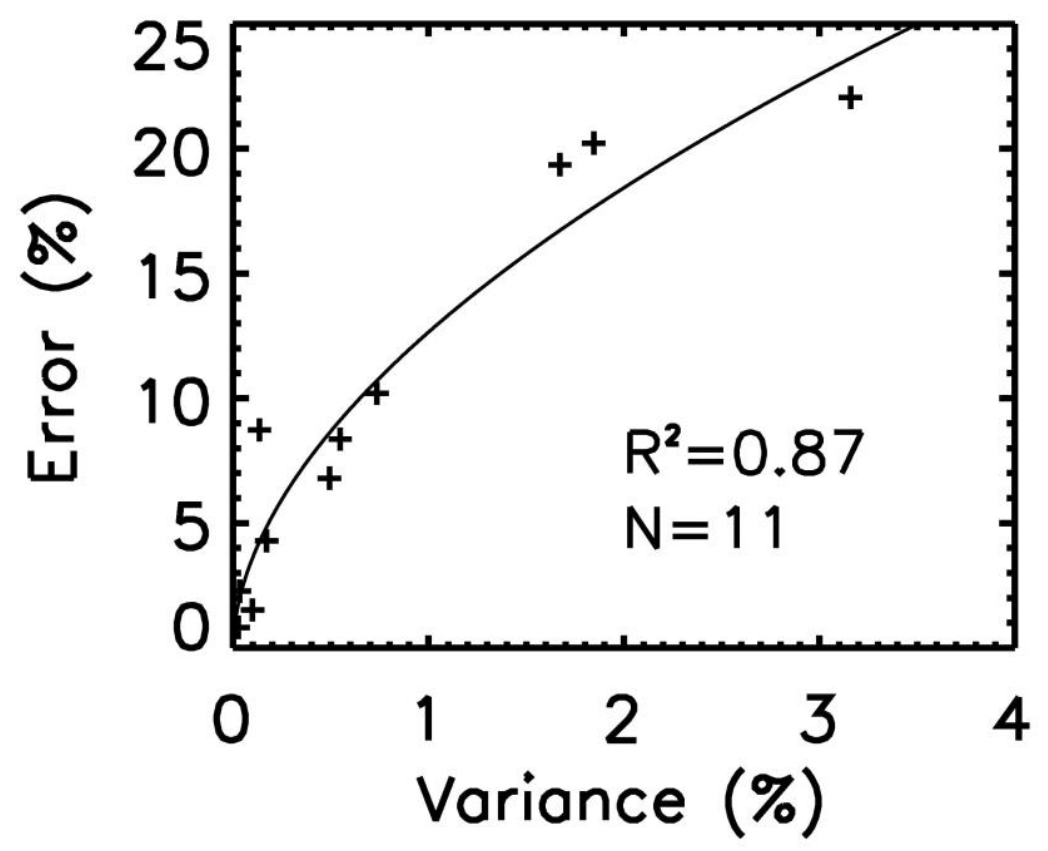

Figure 3. 